\title{
Changing oral health knowledge and habits of kindergarten educators within the oral health promotion program for preschool children
}

\author{
Peter Bakardjiev, Liliya Doichinova
}

1. Department of Pediatric Dental Medicine, Faculty of Dental Medicine, Medical University, Sofia;

\begin{abstract}
Introduction:

Educators should be involved in children oral health education due to the fact that the children spend a significant amount of time with them in the kindergarten, where they could be taught good health habits. They could emphasize and consolidate knowledge about the significance of sugary snacks and drinks, the benefits of a healthy diet, good oral hygiene habits and dental visits.
\end{abstract}

\section{Material and methods:}

49 people took part in the study - 24 educators and 25 support staff in kindergartens. Didactic trainings were organized for them in the course of three weeks.

\section{Aim:}

The aim of the study was to establish the changes in the knowledge and skills of kindergarten pedagogical and support staff about oral hygiene procedures and dietary habits in the course of the dental health promotion program for preschool children.

\section{Results and discussion:}

As a result of the trainings for kindergarten educators and staff who took part in the experiment, as part of the oral health promotion program for preschool children, significant improvement of own knowledge and changes in oral hygiene habits and healthy eating habits were observed. 


\section{Conclusion:}

By positively influencing kindergarten educators' own oral hygiene and diet, significant improvement of these oral health factors is expected for the children under their care, as well. The positive change is also significant due to the fact that the pedagogical staff is an integral part of the people implementing the oral health promotion program.

Keywords: promotion, oral health, pedagogues, preschool age.

\section{Introduction}

Changing poor oral health habits is a difficult process, which should be organized with the cooperation of specialists, parents, teachers and educators. Early childhood is the time when most habits are established for life (1). It offers the greatest opportunity to prevent diseases, which in turn can contribute for better health in adulthood $(2,3,4)$. Data from some researchers show that good oral health behavior during childhood leads to better oral health in later years (5).

Although parents play the most important role for their children's oral health, teachers should also be involved in children's oral health education $(6,7,8,9)$. Children spend a significant amount of time in schools and kindergartens, where they can be taught good healthy habits (7). Teachers could emphasize and consolidate knowledge about the significance of sugary snacks and drinks consumption, the benefits of a healthy diet, good oral hygiene habits and dental visits (10). Although they are a key factor for the proper implementation of health education, they do not necessarily possess the advance knowledge and skills enabling them to play this role effectively. Successful training of kindergarten staff includes consideration of the main issues identified by the teachers themselves; conducting it in an environment closest to the teacher's working environment; covers theoretical training, demonstrations, practical skills and feedback; support from colleagues and the educational institution as a whole; enhancing the selfconfidence of the participants; conducting it for a sufficient period of time; providing opportunities for feedback and reflection; conscious commitment on the part of teachers; building skills (9). However, through appropriate training, they could significantly improve the development and implementation of the health promotion program $(11,12,13,14,15)$. Early oral health education and preventive measures also help decrease the need for future treatment of oral diseases (8).

\section{Material and methods}

49 people took part in the study - 24 educators and 25 support staff from the kindergartens where an oral health promotion program was being implemented. During the program, didactic trainings for the educators and support staff were organized in the course of three weeks. The first week, a 60-minute training on the causes of oral diseases was carried out. The second week - theoretical training on their role in transferring oral hygiene knowledge and practical training on carrying out oral hygiene procedures, means and methods, with a duration of 60 minutes; and the third week - a 60-minute training on the relation between nutrition and dental caries activity. The trainings were carried out in the kindergartens which participated in the experiment. 
A survey was carried out among kindergarten educators and staff on their knowledge and behavioral habits regarding oral hygiene and diet. The survey was carried out before the beginning and after the end of the experimental period.

Table 1. Survey for educators and supports staff

\begin{tabular}{|l|l|}
\hline $\begin{array}{l}\text { 1. When do you brush your teeth? } \\
\text { a. In the morning / evening }\end{array}$ & \\
b. In the morning and in the evening & \\
\hline 2. How long do you brush your teeth for? & \\
a. One minute & \\
b. Two minutes & \\
c. More than two minutes & \\
\hline 3. Do you observe any sequence when brushing your teeth? \\
a. Yes \\
b. No & \\
4. Do you snack between meals? & \\
a. Yes & \\
b. No & What snacks do you have between meals? \\
a. Candy & \\
b. Sweets & \\
c. Fruit & \\
\hline
\end{tabular}

\section{Aim}

The aim of the study was to determine the changes in the knowledge and skills regarding oral hygiene procedures and eating habits of the kindergarten pedagogical and support staff in the course of the dental health promotion program for preschool children. 


\section{Results and discussion}

Figure 1. Tooth brushing frequency for the kindergarten staff

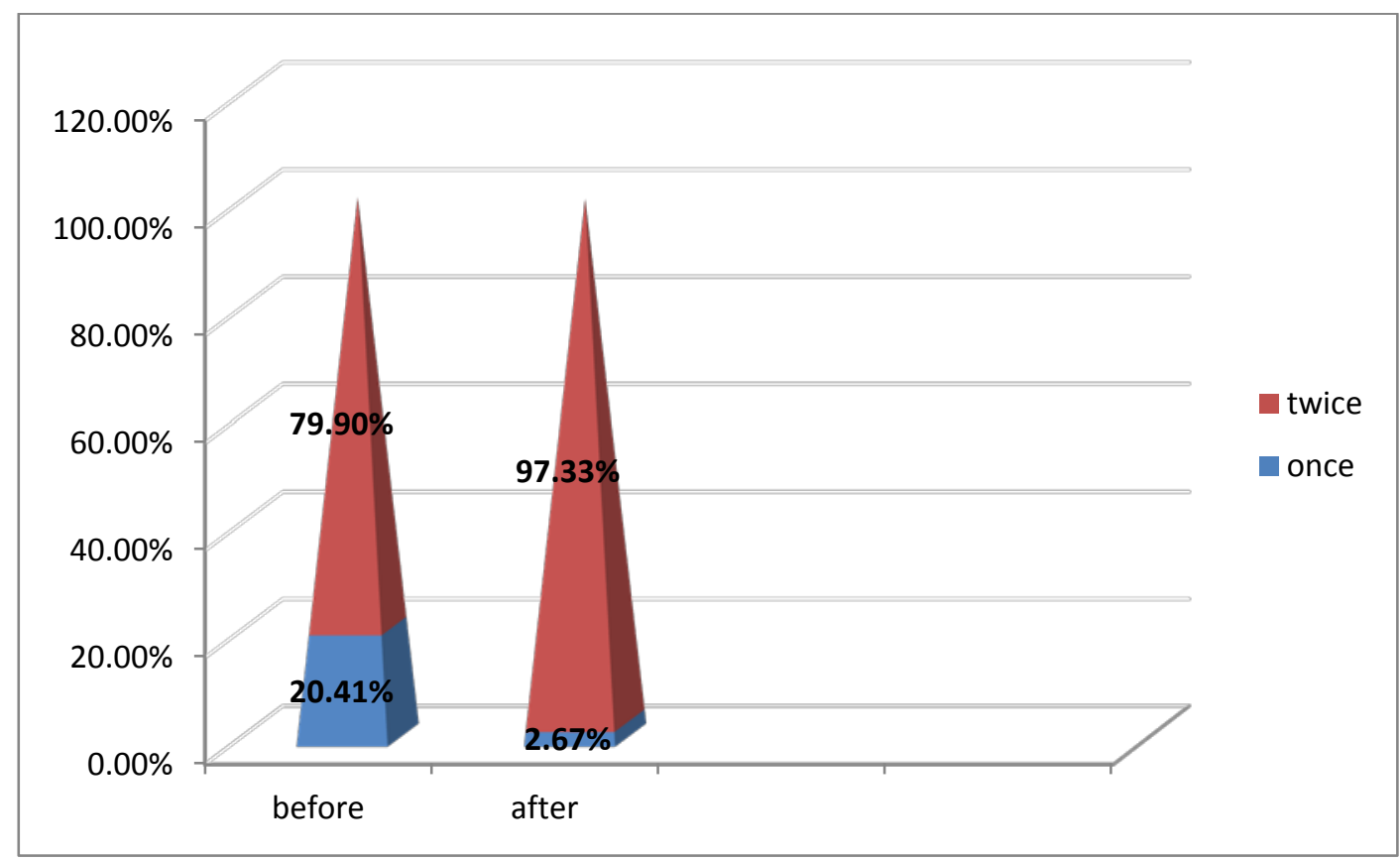

The above figure shows that the frequency of daily tooth brushing was significantly impacted after program implementation $(T=2.85, p<0.01)$.

Figure 2. Tooth brushing duration for the kindergarten staff

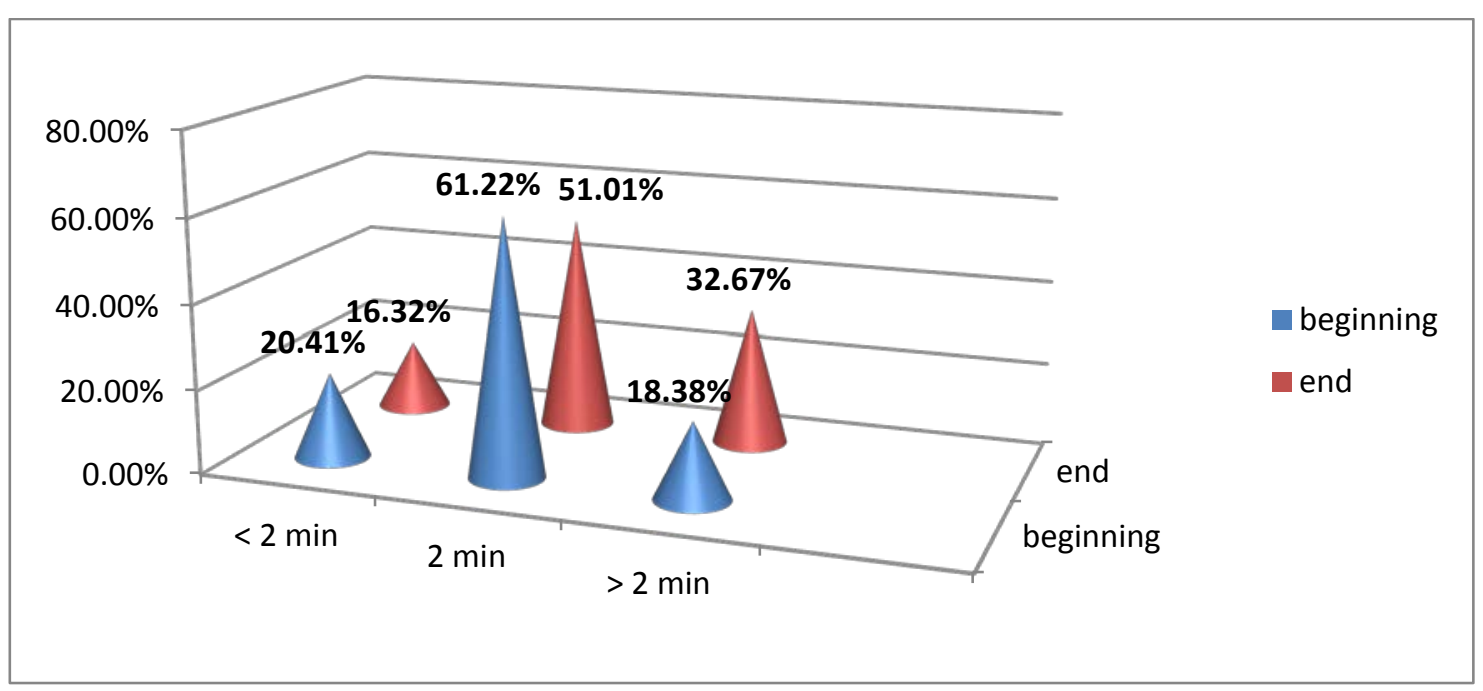


The duration of tooth brushing was also affected by the implementation of the oral health promotion program, but the difference was not significant.

The findings show less cases when they brush their teeth for less than two minutes, less cases when they brush their teeth for two minutes, and an increase in the number of cases who started to brush their teeth for more than two minutes, but no significant differences were found $(T=1.68, p>0.05)$. This shows that the kindergarten staff is relatively difficult to influence in terms of changing their habits regarding tooth brushing duration.

Figure 3. Sequence in tooth brushing

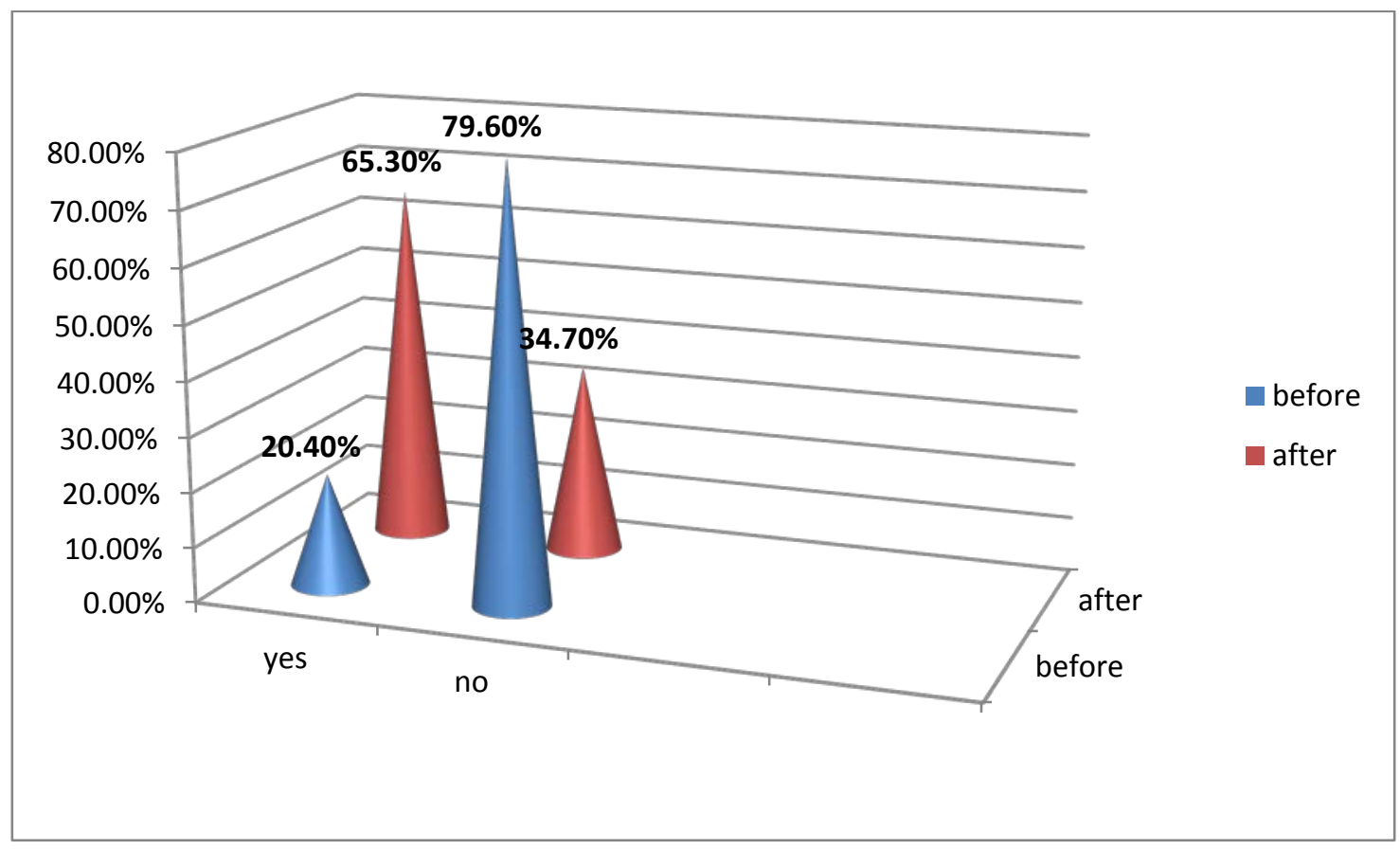

Significant impact is observed for establishing a sequence in tooth brushing. There is a significant increase in the cases who started applying a certain sequence, and a decrease of those who do not $(T=5.04, p<0.001)$. 


\section{Figure 4. Snacks}

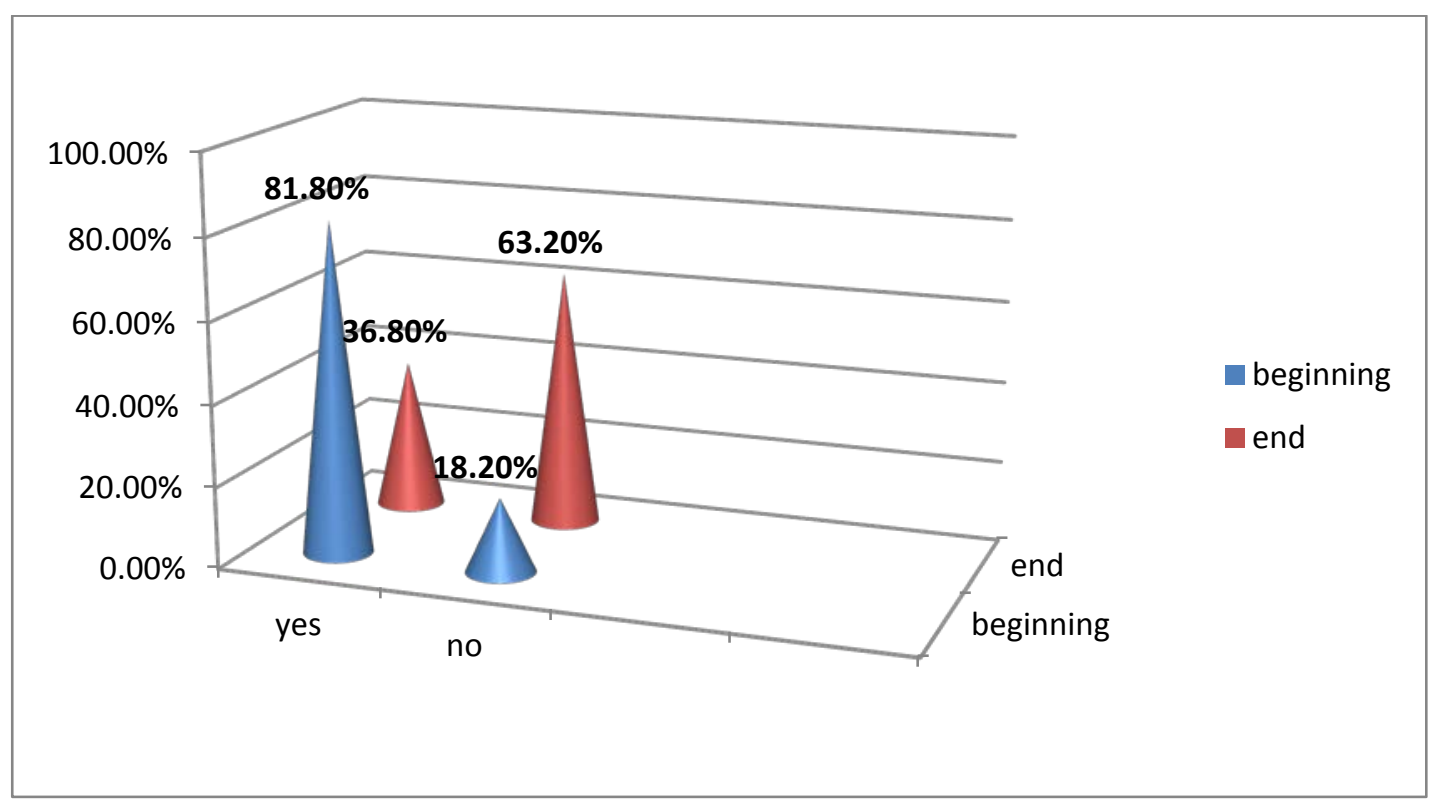

In terms of eating habits, it can be seen that after the experiment, there is a significant decrease in the number of kindergarten staff who snacked between meals, and an increase in those who do not anymore $(T=5.10, p<0.001)$.

Figure 5. Type of snacks

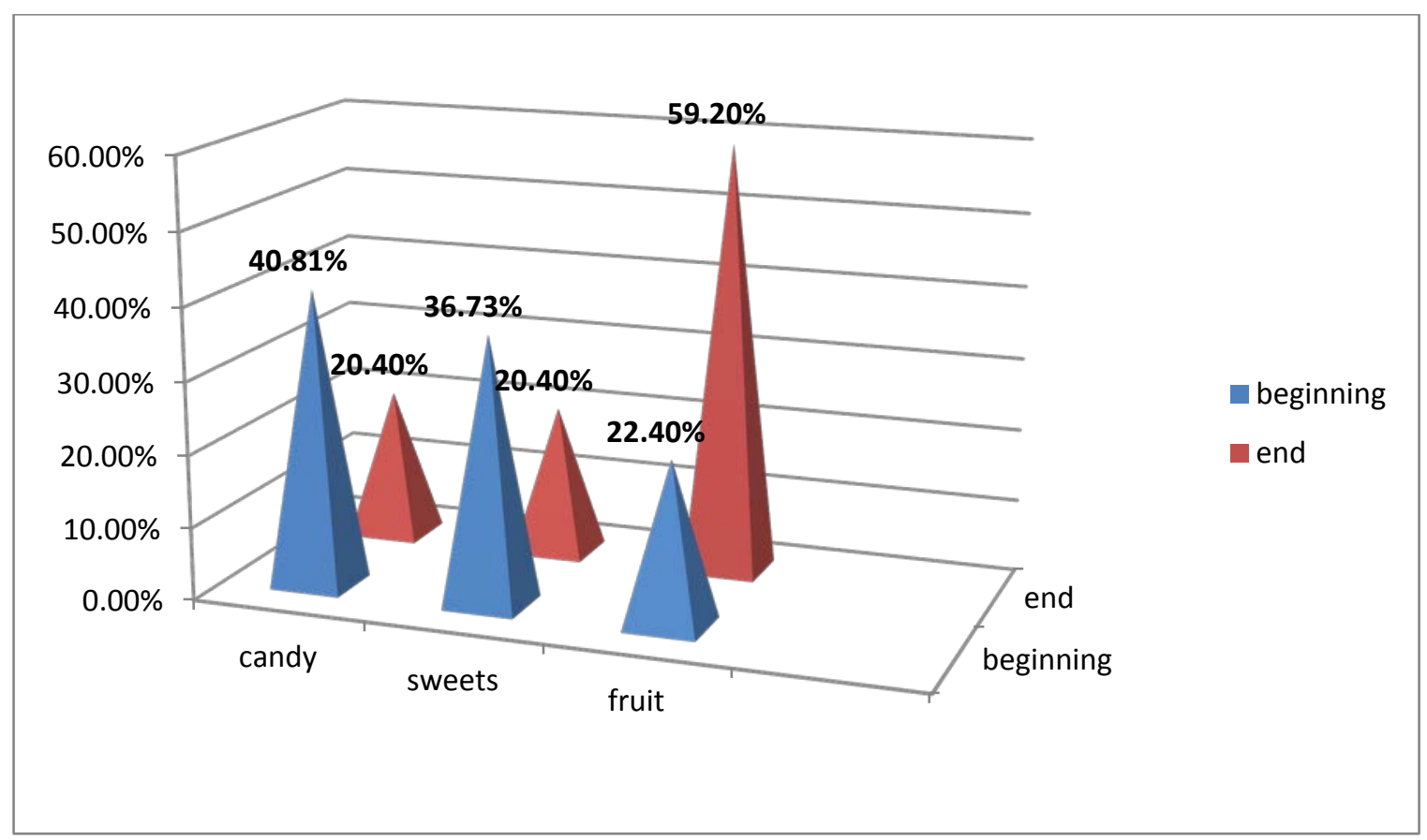


The findings about the type of snacks show that while in the beginning most people had candy, followed by sweets and the least - fruit, in the end the largest part now have fruit as snacks (significantly more $T=5.10, p<0.001)$, and candy and sweets were reduced significantly $(T=2.25, p<0.01)$.

\section{Conclusion}

The study of kindergarten staff habits shows that as a result of including them in the oral health promotion program for preschool children, there is a positive impact on their own oral hygiene and diet. It is also expected that this will lead to more and more prominent recommendations, involvement and control on the oral hygiene procedures of the children under their care. The data obtained from the responses at the beginning and at the end of the study period are statistically significant. The positive change is of significant importance for the educators and staff, since they are responsible for the implementation of the oral health promotion program in kindergartens.

\section{Implications}

The methods applied in the oral health promotion program for preschool children achieve significant improvement of the oral health knowledge of kindergarten educators and staff, which in turn is a prerequisite for improving this knowledge in the children under their care.

\section{References}

1. Oral Health Promotion Strategic Plan 2012-2017, Oral Health Services Tasmania. Available at: http://www.dhhs.tas.gov.aul

2. Centres for Disease Control and Prevention. Guidelines for s2chool health programs to prevent tobacco use and addiction. MMWR Morb Mortal Wkly Rep 1994; 43 (RR-2): 1-18.

3. Currie C, Hurrelmann K, Settertobulte et al. Health and Health Behaviour among Young People. WHO Policy Series: Health policy for children and adolescents Issue 1, International Report. Copenhagen: WHO Regional Office for Europe 2000.

4. Heckman, JJ. Investing in Disadvantaged Young Children is Both Fair and Efficient. Presented to the Committee for Economic Development, the Pew Charitable Trusts, PNC Financial Services Group, New York City 2006.

5. Wind $M$, Kremers S, Thijs $C$ et al. Toothbrushing at school: effects on tooth brushing behaviour, cognitions and habit strength, Health education 2005; 105(1):53-61.

6. Petersen PE. Global policy for improvement of oral health in the 21st century - implications to oral health research of World Health Assembly 2007, World Health Organization. Community Dent Oral Epidemiol. 2009;37(1):1-8.

7. Rajab LD, Petersen PE, Bakaeen $\mathrm{G}$ et al. Oral health behaviour of schoolchildren and parents in Jordan. Int J Paediatr Dent 2002;12(3):168-176.

8. Vigild M, Petersen PE, Hadi R. Oral health behaviour of 12-year- old children in Kuwait. Int J Paediatr Dent. 1999; 9(1): 23-9.

9. World Health Organization. Information Series On School Health, Document Eleven. Oral Health Promotion: An Essential Element of a Health-Promoting School. Geneva: WHO, 2003. 
10. Denman S, Moon A, Parsons C et al. The Health Promoting School. Policy, Research and Practice. London, Routledge Falmer 2002.

11. Dental Health Foundation, Ireland. Oral Health in Disadvantaged Schools in the Eastern Region. Dublin: Dental Health Foundation, Ireland 2001.

12. Nyandindi US. School health education in Tanzania. In Blegvad L, Ringsted F. (eds). Report from the Workshop on Health Care Systems in Africa: Patterns and Perspectives. Proceedings from the University of Copenhagen, North-South Initiative Workshop, April, Copenhagen: The ENRECA Health Network 1998: 27-29.

13. Nyandinidi $U$, Palin-Palkas $T$, Milen A et al. Participation, Willingness and abilities of schoolteachers in oral health education in Tanzania. Community Dent Health 1994;11(2):101-4.

14. Wierzbicka M, Petersen PE, Szatko F et al. Changing oral health status and oral health behaviour of schoolchildren in Poland. Community Dent Health 2002;19(4):243-50.

15. World Health Organization. Strategies and approaches in oral disease prevention and health promotion, 2014. Available at: http://www.who.int/oral health/strategies/cont/en/

\section{Corresponding author:}

Dr. Peter Bakardjiev, DM

Departament of pediatric dental medicine, Faculty of dental medicine, Medical University Sofia, 1 St. Georgi Sofiiski str.

Sofia, Bulgaria

email: bucki_tuz@yahoo.com 